\title{
Pierre Hadot e os exercícios espirituais: a filosofia entre a ação e o discurso
}

\author{
Pierre Hadot and the spirituals exercises: \\ the philosophy between action and speech
}

\section{Fábio Ferreira de Almeida}

Doutor em Filosofia pela Universidade do Estado do Rio de Janeiro (UERJ), professor adjunto da Universidade Federal de Goiás (UFG), Goiânia, G0 - Brasil, e-mail: fabio.almeida@ufg.br

\section{Resumo}

O objetivo do presente artigo é analisar a noção de exercícios espirituais que o filósofo, filólogo e historiador Pierre Hadot elabora a partir de seus estudos acerca do pensamento antigo. Sobressai da ideia de exercícios espirituais, que marcou tão profundamente a filosofia de Michel Foucault, a relação entre ação e discurso, relação essa que configura a compreensão do que seja a própria filosofia. Compreender a filosofia como exercício espiritual a liga intimamente à vida, o que lhe confere tanto mais intensidade. Considerase também aqui a indissociabilidade entre filosofia e história na obra de Hadot, traço que distingue seu pensamento e que vem acrescentar a ele uma nota suplementar de exigência e de rigor.

Palavras-chave: Exercícios espirituais. Filosofia. Ação. Discurso. Vida. 


\section{Abstract}

The aim of this paper is to analyze the notion of spiritual exercises which the philosopher, philologist and historian Pierre Hadot draw in their studies about ancient thought. Stands the idea of spiritual exercises, which so deeply marked the philosophy of Michel Foucault, to the relationship between action and speech, that constitutes an understanding about what is philosophy itself. Then philosophy acquire much more intensity when understand as spiritual exercise, because intimately linked to life. The connection between philosophy and history in the work of Hadot is also considered, something that distinguishes his thinking and that it adds an additional note of requirement and precision.

Keywords: Spiritual exercises. Philosophy. Action. Speech. Life.

\section{Levar o real até a ação como uma flor desliza para a boca ácida das crianças novas. Conhecimento inefável do diamante desesperado (a vida).}

(René Char)

Pierre Hadot talvez seja um desses pensadores a partir dos quais pode ser colocada novamente uma questão já velha: a questão da filosofia ela mesma, ou seja, o problema do lugar da filosofia diante, por exemplo, da história, da literatura, da ciência. Poder-se-ia perguntar qual, ou o que é, a filosofia de Pierre Hadot? Essa questão, que pode parecer apressada, talvez tenha um sentido, ou antes um valor metodológico: ela nos mostra que é necessário recuar, com um sorriso filosófico, diante da imponência da palavra "filosofia", atitude que também a obra de outros filósofos requer. Uma passagem da entrevista a Arnold Davidson, publicada no volume La philosophie comme manière de vivre com o título "De Socrate à Foucault", ilustra bem o que pretendo dizer. Quando perguntado a propósito de suas divergências com Foucault, Hadot responde:

é preciso ressaltar antes de tudo que nossos métodos eram muito diferentes. Foucault era, sem dúvida, ao mesmo tempo que filósofo, um 
historiador dos fatos sociais e das idéias, mas ele não havia praticado a filologia, isto é, todos os problemas ligados à tradução dos textos antigos, à decifração dos manuscritos, ao problema das edições críticas, da escolha das variantes textuais. Editando e traduzindo Marius Victorinus, Ambrósio de Milão, os fragmentos do comentário do Parmênides, Marco Aurélio, alguns tratados de Plotino, adquiri certa experiência que me permitia abordar os textos antigos de uma perspectiva completamente distinta da dele. Em especial, sempre dei muita importância ao cuidadoso estudo do movimento do pensamento do autor e à busca de suas intenções (HADOT, 2008a, p. 216).

Não se pode, evidentemente, afirmar com isso que a filologia está para o pensamento de Hadot do mesmo modo que a história está para o pensamento de Foucault. Com efeito, a reflexão de ambos reserva à história um papel decisivo. Entretanto, a história que faz Hadot carrega consigo esse traço, que nos parece determinante, da filologia, de uma atenção redobrada para o movimento do pensamento e a intenção de cada autor em questão. Eis a história que Hadot pratica, não tão distante, mas ligeiramente diferente da que pratica Foucault. Contudo, o que a minúcia, a paciência, o rigor científico desse trabalho filológico acrescenta à démarche do historiador, do filósofo? Uma resposta a essa pergunta encontramos no final da mesma entrevista:

concretamente, os historiadores da filosofia estudam filosofias e obras filosóficas. Pessoalmente, tendo a estudar, não tanto as filosofias, mas, sobretudo, as obras filosóficas, pois duvido da possibilidade de reconstruir com exatidão corpos de doutrinas filosóficas, ou de sistemas. Podemos apenas estudar a estrutura das obras e a finalidade delas, o que o filósofo quis dizer nesta ou naquela determinada obra. Para tomar o exemplo de um filósofo moderno, como Bergson, é impossível descobrir uma coerência absolutamente perfeita entre seus diferentes escritos. Quando afirmo que o filósofo deve sempre permanecer vivo no historiador, quero sobretudo dizer que, em cada obra de um filósofo, é necessário tentar reviver integralmente, em si, a démarche filosófica do autor, a um só tempo o movimento do pensamento e, se possível, todas as intenções do autor. O estudo desta démarche permitirá, talvez, reconhecer os dois pólos da atividade filosófica, o discurso e a escolha de vida (HADOT, 2008a, p. 227). 
Sem evidentemente pretender desenvolver um estudo comparativo entre Foucault e Hadot, podemos então dizer que: se o primeiro é, ao mesmo tempo que filósofo, um "historiador dos fatos sociais e das ideias", o segundo só é historiador na medida em que filosofa ou, para empregar aqui a expressão consagrada por Martial Guéroult, na medida em que essa história se constitui como filosofia da história da filosofia. ${ }^{1}$ Deve-se entender essa perspectiva não como um esforço por reviver o autor que se estuda, que se comenta, que se traduz, mas como essa exigência filológica de fazer com que o filósofo - seu pensamento, sua obra - permaneça vivo no historiador, que a leitura que se faz de uma obra seja como uma releitura da obra pelo seu próprio autor.

Se nos for permitido agora retomar a pergunta que nos colocávamos inicialmente - qual ou o que é a filosofia de P. Hadot? -, poderemos responder que é esse estudo minucioso, esse esforço para reviver intimamente e com isso atualizar o pensamento e as intenções de um autor. Sabemos quais são esses autores. Dentre eles destacam-se, sobretudo, Plotino e Marco Aurélio, mas também Sêneca e Epicteto. Esse trabalho é histórico porque realiza, assim, a reconstituição do pensamento expresso por um autor em uma determinada obra e, ao mesmo tempo, a atualização desse pensamento em uma época distante daquela na qual foi originalmente concebido, sem perder de vista que essa $a t u$ alização é sempre fruto disso que já podemos reconhecer como esforço de objetividade, esforço que exige cautela, pois "é extremamente importante não cometer anacronismo na pressa de dar a um texto um sentido atual" (HADOT, 2008a, p. 115-116).

E, ainda, tal história só é possível na medida em que possibilita a constituição mesma de um pensamento, isto é, a partir de uma obra determinada, repete-se a questão decisiva: o que é a filosofia? É nesse sentido que o que encontramos na obra de Pierre Hadot é, de fato, uma filosofia, mas essa filosofia não é, senão, uma filosofia que se funda na

0 problema do estruturalismo parece não se colocar para a filosofia de P. Hadot e a passagem citada há pouco parece confirmá-lo. Até onde sei, Guéroult não é citado por Hadot e o método estruturalista não é discutido por ele, ainda que 0 nome de Victor Goldschmidt seja recorrente. Isso talvez se explique pelo fato deste ter se dedicado ao pensamento antigo, ao passo que Guéroult consagrou seus estudos à filosofia moderna.

Rev. Filos., Aurora, Curitiba, v. 23, n. 32, p. 99-111, jan./jun. 2011 
"vivência", ou no esforço em vivenciar o pensamento expresso na obra de um filósofo. Em outras palavras, ela se constitui, de fato, como uma filosofia da história da filosofia ou, no caso preciso de Hadot, uma filosofia da história da filosofia antiga. Esse parece ser o traço distintivo que a prática da filologia acrescenta ao pensamento e libera o tema latente da leitura. Trata-se, então, de um exercício de leitura que forma, que constitui pensamento.

Com isso, Hadot pode ser reconhecido na vizinhança de autores, além de Foucault, Nietzsche, Heidegger e ainda outros. Não por acaso, a última parte do artigo Exercices spirituels, de 1976 - artigo que the valeu, como sabemos, a indicação, por iniciativa do próprio Foucault, para a cadeira intitulada "História do pensamento helenístico e romano" do Collège de France ${ }^{2}$-, intitula-se precisamente "Aprender a ler". Ora, esse privilégio reconhecido à leitura nos remete novamente à conexão entre pensamento e história marcada ou regulada pela filologia. Se a história já deve ser entendida como exercício de leitura sem o qual não há filosofia, a filologia vem sobrecarregar esse exercício, vem torná-lo ainda mais exigente, ela demanda ainda maior esforço daquele que a pratica.

Diria que é na obra de 2004, Le voile d'Isis, que Pierre Hadot fornece a forma mais acabada dessa prática - por que não dizê-lo, desse exercício - de leitura. O livro é resultado dos cursos ministrados no início de suas atividades como professor do Collège de France, e que, segundo o próprio autor, há muito vinha sendo planejado. Nessa obra, percebe-se com clareza aquele papel que a leitura desempenha em seu pensamento. Seu subtítulo já é significativo, trata-se de um "Ensaio sobre a história da ideia de natureza". Temos aí uma história, mais precisamente a história de uma ideia. A marca da filologia aparece, penso, não na ideia da qual se pretende fazer essa história, mas antes na démarche adotada: o que está em jogo é, de fato, uma "leitura" de como

2 Em 2006 foi publicado o texto da aula inaugural pronunciada por Hadot, Eloge de la philosophie antique, na qual 0 autor ressalta 0 fato de no Collège se primar por um "ensino e pesquisa que mantém em estreita ligação orientações freqüentemente separadas de maneira artificial: 0 latim e 0 grego, a filologia e a filosofia, 0 helenismo e 0 cristianismo". (HAD0T, 2006, p. 9) 
o famoso aforismo 123 de Heráclito, physis kriptesthai philein (que se traduz geralmente por "a natureza ama esconder-se"), atravessou toda a cultura ocidental, como servindo-lhe de fio condutor. Ao final do prefácio à obra, Hadot esclarece:

é no quadro da história destas metáforas e de seus lugares-comuns que o presente estudo se inscreve, seja no que diz respeito à fórmula 'A natureza ama esconder-se', às noções de véu e de desvelamento, ou à figura de Isis. Estas metáforas e estas imagens inspiraram e, ao mesmo tempo, influenciaram a atitude do homem em relação à natureza (HADOT, 2008b, p. 18).

Em suma, é a atitude do homem em relação à natureza que determina a filosofia de P. Hadot, e o livro Le voile d'Isis mostra, por meio do mesmo movimento de pensamento, o sentido dessa preocupação e o estilo com que é tratada, ou seja, como a ideia de natureza é lida nas obras que atravessam o pensamento e a cultura ocidentais e seus efeitos sobre a própria reflexão, que, lendo, faz a sua história.

A já conhecida fluência do estilo quase contrasta com a profunda erudição, características, aliás, de todos os trabalhos do filósofo. Percorrem-se as mais de 400 páginas de Le voile d'Isis com um fio condutor muito nítido: como já indicamos, a ideia de natureza. Filosofia, religião, artes e ciência vêm aí testemunhar as transformações da recepção e da representação dessa ideia. "Escrever a história de sua recepção", afirma Hadot, "é escrever a história de uma sequência de contra-sensos, mas de contra-sensos criadores, na medida em que estas três palavrinhas se prestaram a expressar, mas talvez a também mostrar perspectivas sempre novas sobre a realidade e, também, atitudes muito diversas em relação à natureza, admiração ou hostilidade ou angústia" (HADOT, 2008b, p. 404).

Eis o que justifica o esforço empreendido nessa obra: não se trata aí de discutir os diversos modos dessa recepção para propor um a mais, por mais novo e original que pudesse ser; também não se trata de sublinhar descontinuidades epistemológicas na história dos modos de representação da natureza, por mais que a noção de "contra-senso" possa ser aproximada dessa ideia. Se Hadot se interessa pela ideia de natureza, 
não é senão movido por aquilo que aprendeu nessa peculiar frequentação da filosofia antiga, um traço que reaparece sempre ao longo dos séculos, que é ressaltado pela história e que constitui a preocupação diretora, podemos dizer, de suas pesquisas. Essa preocupação se expressa de modo exemplar, por exemplo, no silêncio com que Wittgenstein encerra seu Tractatus logico-philosophicus, que é, de algum modo, análogo à sabedoria de Sócrates, que, como afirma no discurso em sua defesa, "reconhece não valer, realmente, nada no terreno da sabedoria" (PLATÃO, 2001, 23b 1), o que dá sentido ao preceito délfico: ser o que realmente é e ao oracular gnôthi seautón (PLATÃO, 2001, p. 22-25).

Tal preocupação, de Sócrates a Wittgenstein, passando por Agostinho, Pascal, Goethe e Nietzsche, constitui uma tradição que envolve filosofia, ciência, religião, arte e se pergunta fundamentalmente pela prática, pela ação entendida como modo ou estilo de vida, o que remonta à ideia de conversão, isto é, o modo como a ideia expressa por um discurso repercute na vida prática; um sentimento de si plasmado no sentimento do mundo. Esse aspecto, com efeito, poderia nos levar a reconhecer aí um pensamento que se situa para além da ética, e quem sabe mesmo não ético, na medida em que o privilégio reconhecido à prática aboliria a necessidade de uma formulação teórica, isto é, uma reflexão a respeito de conceitos como bem, mal, justo, etc. Tal impressão não é mais que aparente, uma vez que, aí, não se prescinde, não se pode prescindir de teoria, pois "se for suprimida toda referência dogmática e teórica, o indivíduo se encontra completamente abandonado a si mesmo" (HADOT, 2002, p. 387), donde a necessidade de modelos, de exemplos de vida para guiar decisões complexas com as quais o indivíduo se depara, para orientar a escolha de vida.

É no sentido dessa prática que necessita de modelos, de teorias e até de dogmas, que reencontramos Le voile d'Isis: o tema geral dessa obra não é propriamente a ideia de natureza, não é uma exegese nem do aforismo de Heráclito nem da imagem de Isis, e tampouco das metáforas do véu e do desvelamento. $\mathrm{O}$ tema geral da obra é precisamente esse confronto entre o discurso e a prática, entre o pensamento e a vida, enfim, entre a experiência e a ideia. É o que reserva ao leitor o último parágrafo da obra: 
o leitor terá, de passagem, percebido os temas que me seduzem e sobre os quais me demorei, talvez um pouco demasiadamente: uma idéia e uma experiência. Uma idéia: a natureza é arte e a arte, natureza, não sendo, assim, a arte humana mais que um caso particular da arte da natureza; idéia que acredito nos permitir melhor compreender o que pode ser a arte e, ao mesmo tempo, o que pode ser a natureza. Uma experiência: a mesma de Rousseau, de Goethe, de Hölderlin, de Van Gogh, e de tantos outros; a experiência que consiste em tomar intensamente consciência do fato de que fazemos parte da natureza, que neste sentido somos nós mesmos esta natureza infinita e indizível que nos engloba totalmente. Lembremos Hölderlin: "Unificar-se com todas as coisas vivas, retornar, por um radiante esquecimento de si, ao Todo da Natureza"; lembremos Nietzsche: "Ultrapassar a mim mesmo e a ti mesmo. Experimentar de uma maneira cósmica" (HADOT, 2008b, p. 408).

Não é isso o sentimento do excesso - tema tão bem explorado por Bataille -, o sentimento de que, pertencendo à natureza, o homem é ultrapassado por ela? Não é precisamente aí, nessa confluência de ideia e experiência, que desaba sobre o homem, simultaneamente, a certeza da finitude, portanto de sua fragilidade, de sua provisoriedade, e o imenso inapreensível da natureza, que o reduz ainda mais a essa mínima parte dela, que ele é? Uma ideia e uma experiência, dizer a natureza e senti-la em si, não é precisamente isso que Hadot destaca como exercício espiritual? Uma vez que se referem ao homem, mas ao homem como parte da natureza, ideia e experiência, como, aliás, discurso filosófico e vida filosófica, são, assim, incomensuráveis, mas ao mesmo tempo inseparáveis. E é isso que, segundo Hadot, faz da filosofia antiga um fenômeno singular, um acontecimento único. Temos então o tema inteiro da obra Qu'est-ce que la philosophie antique?, da qual nos será escusado citar esta passagem um tanto longa:

vida filosófica e discurso filosófico são incomensuráveis, sobretudo, por serem de ordem totalmente heterogênea. O que é essencial à vida filosófica, a escolha existencial de um certo modo de vida, a experiência de certos estados, de certas disposições interiores, escapa totalmente à expressão do discurso filosófico. Isso aparece claramente na experiência platônica do amor, talvez até na intuição aristotélica das substâncias simples e, sobretudo, na experiência unitiva plotiniana, totalmente 
indizível em sua especificidade dado que aquele que fala dela, uma vez terminada a experiência, já não se situa no mesmo nível psíquico de quando ele vivia a experiência. Mas isso vale também para a experiência de vida epicurista ou estóica ou cínica. A experiência vivida do puro prazer, ou da coerência consigo mesmo e com a Natureza, é de ordem completamente distinta do discurso que a prescreve ou que a descreve do exterior. Tais experiências não são da ordem do discurso e das proposições (HADOT, 2008d, p. 267-268).

Diria que é pelo homem que ideia e experiência, assim como discurso e vida, são incomensuráveis. Entretanto, é pela natureza que os elementos desses pares são inseparáveis. Com efeito, o discurso contém ideias, ainda que apenas em certa medida, mesmo que de modos que podem variar em precisão e clareza. Eles são, portanto, comensuráveis. $\mathrm{O}$ mesmo se pode dizer de experiência e vida. Contudo, jamais discurso algum será bastante para a vida, qualquer que seja ela, do mesmo modo que nenhuma ideia jamais equivalerá a uma experiência. O paradoxo não se resolve; a antinomia persiste, e isso precisamente porque seus termos são inseparáveis. Essa é a singularidade disso que, na Antiguidade, apareceu como filosofia: foi nesse momento que, pela primeira vez, a constrangedora unidade desses elementos incomensuráveis e inseparáveis colocou o homem em contato com a natureza:

não há discurso que mereça ser chamado de filosófico, se está separado da vida filosófica; esta também não existirá se não estiver estreitamente ligada ao discurso filosófico. É aí que, aliás, reside o perigo inerente à vida filosófica: a ambigüidade do discurso filosófico (HADOT, 2008d, p. 268).

A filosofia significa, portanto, uma ameaça constante, um perigo imanente, que se apresenta, pela ambiguidade, à ideia e ao discurso; e pela morte, à experiência e à vida. A ambiguidade, a ameaça, o perigo, então, é o que distingue o encontro do homem com a natureza nesse espaço difuso e estreito que é a filosofia. Eis por que, em seu alvorecer, a filosofia foi, e deve, ser lida como exercício; é esse perigo e essa ameaça que obrigam o espírito a práticas que, como a conversão, a ascese, 
visam ao si-mesmo, isto é, ao interior do homem e o outro, aquilo que o cerca, tudo com que se relaciona. Enquanto prática, enquanto exercício, a filosofia é um aprendizado e isso confere toda singularidade e exemplaridade à figura de Sócrates: ele não queria, como afirma em sua Defesa, ensinar nada, mas apenas aprender. Esse aprendizado é que dá sentido à ideia, muitas vezes repetida por P. Hadot, de que, "no diálogo 'socrático', a verdadeira questão que está em jogo não é do que se fala, mas aquele que fala" (HADOT, 2002, p. 39).

Não podemos nos esquecer que, na expressão "exercício espiritual", o acento deve recair sobre o primeiro termo. Trata-se efetivamente de exercício, no sentido mesmo físico, biológico e corporal do termo. Vem daí o significado terapêutico da filosofia tal como é concebida, por exemplo, pelo estoicismo e pelo epicurismo. É nesse sentido que, como afirma Hadot, "compreende-se bem que uma filosofia, como o estoicismo, que exige vigilância, energia, tensão de alma, consiste essencialmente em exercícios espirituais" (HADOT, 2002, p. 33). Todo esse aprendizado, essa exigente terapêutica em relação ao corpo e à alma, coloca o homem, em primeiro lugar, em relação consigo mesmo e, necessariamente, em relação com o outro. Daí a conexão entre as quatro seções que compõem o artigo Exercices spirituels: "aprender a viver", "aprender a dialogar", "aprender a morrer", "aprender a ler". É preciso enxergar que não há nisso nenhuma ordem, nenhuma progressão. Não há primeiro nem último, pois não são estágios, mas elementos que, naquele espaço que o contato do homem com a natureza abre - a filosofia - se integram, se interpenetram e se complementam. Na verdade, nenhuma distância separa viver e morrer. O êxtase, assim como a angústia, nasce da experiência íntima da natureza. Encontra-se o êxtase, assim como a angústia, igualmente nas práticas da vida e da morte. Novamente, Sócrates aparece como exemplo disso. E como não identificar aí também o amor fati de Nietzsche e a compreensão heideggeriana do Dasein como "ser-para-morte"?

Tais afirmações podem soar contrárias à admiração que Hadot sempre nutriu por Goethe e que expressa em sua última obra, na qual 
destaca a fórmula Gedenken zu leben (N'oublie pas de vivre3): “Esta máxima", afirma ele,

é a tradução de Memento vivere que Goethe opõe a Memento mori. [...] Esta última máxima significa que é preciso pensar num acontecimento futuro para preparar-se para ele. O Memento vivere não é simétrico ao Memento mori, é uma máxima paradoxal" (HADOT, 2008c, p. 271-272).

Aquele que afirma memento vivere, não pode, portanto, afirmar memento mori, já que, com efeito, a vida não pode ser uma preparação para um acontecimento futuro, pois isso quer dizer esquecer a vida mesma, a vida no presente, sua atualidade. É a negação da máxima memento mori que faz do memento vivere uma máxima paradoxal: ela significa, em suma, dizer sim ao devir e ao que é terrificante. De modo que também não se pode ligar o memento mori àquele "aprender a morrer" que a prática de exercícios espirituais exige. Uma passagem do famoso artigo de 1976 parece confirmar isso: "exercitar-se em morrer, é exercitar-se em morrer em sua individualidade, suas paixões, para enxergar as coisas na perspectiva da universalidade e da objetividade. Evidentemente, tal exercício supõe uma concentração do pensamento sobre ele mesmo, um esforço de meditação, um diálogo interior" (HADOT, 2002, p. 49-50), portanto, transformação de si, exercício e aprendizado da ascese.

O problema ou, antes, a questão da filosofia, especialmente quando ela, como na Antiguidade, situa-se na tensão entre ação e discurso, entre a prática e a palavra, é o que faz sobressair para o pensamento a noção de exercício. Com efeito, filosofar deverá ser esse aprendizado sedutor e perigoso. Sócrates se dizia um parteiro de almas; o pensamento deve, com efeito, se aproximar da disposição da criança, atraída irresistivelmente pelo mundo e, quem sabe mais ainda, pelo perigo que o mundo promete. No entanto, como também reconhece o poeta René

3 É difícil trazer para o português a fórmula de Goethe, que recupera a famosa injunção latina: carpe diem. Ocorreme, de imediato, o refrão de uma canção popular: "não pense no amanhã, porque 0 amanhã é agora", que expressa aproximadamente seu sentido. Penso, no entanto, que ela pode ser traduzida por: não esquece que viver é hoje. 
Char, esse risco, essa ameaça constante diante da ação, constitui a própria vida que nenhuma palavra abarca: "levar o real até a ação como uma flor desliza para boca ácida das crianças novas. Conhecimento inefável do diamante desesperado (a vida)".

Com efeito, diante da natureza apresentamo-nos a um jogo alegre, exercício brincante sobre o abismo: eis o que parece ser, afinal, a vida. Eis também como Pierre Hadot compreende a filosofia a partir da Antiguidade greco-latina, e não só isso, mas, e talvez fundamentalmente, como ele pretende mostrar a filosofia ela mesma. Diríamos que o pensamento faz, por um lado, desabar sobre o homem a natureza inteira, sua profundidade e imensidão, mas, por outro lado, do homem explode, na natureza, da qual ele não é mais que uma mínima parte, esse sentimento imenso, inabarcável: sentimento de si, dos outros e do mundo. Na expressão de Hadot, "visão do alto". ${ }^{4}$ A vida, então, é irresistível, mas gozar a vida exige a aceitação de um risco fundamental, significa assumir intimamente a vizinhança da morte. Por isso é necessário aprender a viver e aprender a morrer, sem o que não é possível filosofar. Assim, o carpe diem, do famoso verso de Horácio - "recolha o hoje, pois sabes o quanto é incerto teu amanhã" -, permanece, como vimos, no Memento vivere, de Goethe, mas também em toda palavra que, ciente dos limites da matéria que é a sua, transborda imediatamente de vida, de experiência; vida e experiência que poetas como René Char nos ensinam que é preciso olhar direto nos olhos e, com o coração na boca, seguir.

Ser estóico é imobilizar-se com os lindos olhos de Narciso. Recolhemos todas as dores que por ventura o escritório poderia retirar de cada milímetro de nosso corpo; depois, com o coração na boca, finalmente prosseguimos tendo encarado de frente (CHAR, 2003, p. 4).

4 Regard d'en haut. Essa ideia é elabora por P. Hadot principalmente a partir de seus estudos sobre Plotino, ver notadamente Plotin et la simplicité du regard (GALLIMARD, 1997) e, sobre Marco Aurélio, especialmente em La citadelle intérieure, introduction aux "Pensées" de Marc Aurèle (FAYARD, 1992), retornando em sua última obra, Noublie pas de vivre. 


\section{Referências}

CHAR, R. Feuillets d'Hypnos. In: CHAR, R. Fureur et mystère. Paris: Gallimard, 2003.

HADOT, P. Exercices spirituels et philosophie antique. Paris: Albin Michel, 2002.

HADOT, P. Eloge de la philosophie antique. Paris: Allia, 2006.

HADOT, P. La philosophie comme manière de vivre. Paris: Albin Michel, 2008a.

HADOT, P. Le voile d'Isis. Paris: Gallimard, 2008b.

HADOT, P. N'oublie pas de vivre, Goethe et la tradition des exercices spirituels. Paris: Albin Michel, 2008c.

HADOT, P. Qu'est-ce que la philosophie antique? Paris: Gallimard, 2008d.

PLATÃO. Apologia de Sócrates. Tradução de Carlos Alberto Nunes. Belém: EDUFPA, 2001.

Recebido: 12/09/2010

Received: 09/12/2010

Aprovado: $10 / 12 / 2010$

Approved: 12/10/2010 